\title{
Knowledge, Attitude and Practice towards Religious Obligations among Healthcare Workers in Hospital Langkawi, Malaysia
}

Hafiz J, Dzulkhairi MR, Shamsir MA, Abu N

Faculty of Medicine and Health Sciences, Universiti Sains Islam Malaysia, Jalan Pandan Utama Pandan Indah, 55100 Kuala Lumpur

\begin{abstract}
Introduction: Islamic prayers involve certain physical movements and positions. These positions may be difficult to achieve in Muslim patients who suffer from any illness that limit their physical movements. Therefore, Islam introduced the concept of Rukhsah or exemptions. The objective of this study was to assess the knowledge, attitudes and practices of healthcare workers related to performing prayers during illness. Materials and Methods: A cross sectional study was conducted among 121 healthcare workers in Hospital Langkawi, between $22^{\text {nd }}$ to $24^{\text {th }}$ April 2014. Simple random sampling method was used to select the participants among healthcare workers in Hospital Langkawi to attend a workshop on Rukhsah Ibadah. The participants were given a set of questionnaire to answer and all the data were collected just before the talk began. Results: The majority of the participants $108(89.3 \%)$ were female and more than half of them 74 (61.2\%) were staff nurses. The mean age for the participants was 32.4 (SD: 9.42) years. About 73 (60.3\%) of the participants have good knowledge, 62 (51.2\%) have good attitude and $73(60.3 \%)$ have good practice towards religious obligations and Rukhsah. Bivariate analysis shows no correlation between age and knowledge, attitude and practice score. There was also no correlation seen between knowledge, attitude and practice score. Conclusion: Almost half of the participants have good knowledge, attitude and practice on performing prayers during illness. By conducting proper training and coaching, it is hoped that their level of understanding towards Rukhsah can be improved.
\end{abstract}

KEYWORDS: Health Knowledge, Attitudes, Practice, Islamic prayer, Rukhsah, Patients

\section{INTRODUCTION}

Islam as one of the largest religions in the world is based on five pillars. In a hadith narrated by Ibnu Umar (may Allah be pleased with him), Prophet Muhammad (Peace and Blessing be Upon Him) said that "Islam is based on (the following) five (principles): (1) Shahadah declaration, (2) Five daily prayers, (3) Alms-giving or Zakat (4) Fasting during holy the month of Ramadhan and (5) Hajj or pilgrimage to Mecca (Bukhari)".

As a Muslim, they are obligated to perform five daily prayers. Males are encouraged to pray together (Jama'ah) with others at a nearby mosque while females are preferred to perform their prayers at home. Islamic prayers involved certain movements and positions such as standing, bending, sitting and kneeling. ${ }^{2}$ Nevertheless, these positions

Corresponding author:

Mohd Hafiz Bin Jaafar,

Faculty of Medicine and Health Sciences,

Universiti Sains Islam Malaysia,

Jalan Pandan Utama Pandan Indah,

55100 Kuala Lumpur

Email: dr.hafizjaafar@usim.edu.my

Tel: $+603-42892400$ may be difficult to perform by a Muslim patient who is suffering from any illness that limits their movements. Therefore, Islam introduced the concept of Rukhsah or exemptions. These exemptions are applicable to all forms of religious obligations such as prayers and fasting.

In a hadith narrated by Imran Bin Hussain (may Allah be pleased with him), "I had piles, so I asked the Prophet (Peace and Blessing be Upon Him) about the prayer. He said, "Pray while standing and if you can't, pray while sitting and if you cannot do even that, then pray lying on your side (Bukhari)." 3 From this hadith, it is clearly stated that prayers are still compulsory to Muslim despite any illness. However, the rituals and practices will depend on the person's capabilities. These exemptions allow those with limitations and disabilities to continue praying despite restrictions in movements.

The limitations of performing prayers are not confined to restriction in movements only. Muslims are also required to perform ablution before performing the prayers. In certain conditions, this is not possible due to some medical reason that disallow body parts that are mandatory to be cleaned with water such as face, hands and feet to be in contact with water. Thus, by applying the concept of Rukhsah this ritual can be replaced by 
another mode of purification, called Tayammum. ${ }^{4}$ Allah stated in the Quran: "O you who have believed, when you rise to (perform) prayer, wash your faces and your forearms to the elbows and wipe over your heads and wash your feet to the ankles. And if you are in a state of janabah, then purify yourselves. But if you are ill or on a journey or one of you comes from the place of relieving himself or you have contacted women and do not find water, then seek clean earth and wipe over your faces and hands with it. Allah does not intend to make difficulty for you, but He intends to purify you and complete His favor upon you that you may be grateful." 5 In Tayammum, a clean dust will be applied to face and both hands up to the elbow as a replacement to ablution. ${ }^{4}$

Based on our extensive literature review, no studies had been conducted to show the level of knowledge, attitude and practice among health care workers in Malaysia about religious obligations and Rukhsah. Therefore the objective of this study is to assess the knowledge, attitudes and practices of healthcare workers regarding religious obligation (with a focus on prayers and Rukhsah) in Hospital Langkawi. This information will help us to design a proper training module to empower the healthcare workers with adequate knowledge on prayers so that they will eventually teach the patients and community member to perform their obligatory prayers even when they are sick and incapable to doing it the normal way

\section{MATERIALS AND METHODS}

\section{Study Design}

A cross sectional study was conducted among 121 healthcare workers in Hospital Langkawi, Kedah Darul Aman, Malaysia between $22^{\text {nd }}$ to $24^{\text {th }}$ April 2014. Hospital Langkawi is the only hospital in Langkawi Island and begun its services in 1915. It moved to its new building in 1995 and was officiated by DYMM Tuanku Sultan Kedah Darul Aman in 2002. ${ }^{6}$ This hospital was chosen because the concept of Islamic Friendly Hospital has been introduced to patients. We also received good cooperation and support in terms of facilities, human resources and hospitalities from the hospital management throughout this program.

\section{Sample Selection}

Simple random sampling method was used to select the participants from the list of staff provided by the hospital management. Those who were selected were then invited to attend a workshop on Rukhsah Ibadah. The participants were given a questionnaire to answer and all the data were collected just before the talk began. The inclusion criterion of this study was healthcare workers (nurses, assistant medical officers, doctors, hospital attendants, administrative and allied health staff) who have been working in Hospital Langkawi for more than three months and are Muslims. Those who refused to participate were excluded from this study.

\section{Study Instrument}

A self-constructed questionnaire was used as a measuring tool to collect the data. It was pre-tested among villagers in Mersing in early 2014. The reliability of this questionnaire was calculated using Cronbach's Alpha statistical method with a value of 0.86 . The questionnaire was divided into four parts, which included demographic background, knowledge, attitude and practice of religious obligations and Rukhsah.

The socio-demographic variables were date of birth, age, gender and occupation. Occupation was further divided into nine categories, which included hospital attendant, community nurse, staff nurse, assistant medical officer, radiographer, occupational therapist, medical officer, clinical specialist and others.

There were 24 questions pertaining knowledge. The participants need to choose either they agreed or disagreed with the statements given. They were asked about the basis of Rukhsah for sick people, the concept of ablution and Tayyammum, and also on the performance of prayer among sick people. The questions were then scored 1 for correct answer and 0 for wrong answer. As for the attitude part, a total of 11 questions were included and the scoring was based on the 5-point Likert rating scale. The questions asked included the obligation of performing prayers, the importance of prayers for sick people, performance of ablution/Tayyammum during illness, functions of family members in helping patients to pray and the exemptions or Rukhsah in performing prayers for sick people. For the positive statements, the scores were 5=strongly agreed, 4=agreed, 3=not sure, 2=disagreed, and $1=$ strongly disagreed and for the negative statements, the score were $5=$ strongly disagreed, 4=disagreed, 3 =not sure, 2 =agreed, and 1=strongly agreed. The last part of the questionnaire was practice, which consisted 4 questions. The participants were asked about performance of daily obligatory prayers, performance of prayers and ablution among the sick, and lastly about the cleanliness of the place for praying and clothing. The score given were 2 =good practice, $1=$ moderate practice and $0=$ bad practice. The maximum scores were 24 for knowledge, 55 for attitude and 8 for practice.

\section{Statistical Analysis}

Data from the questionnaire were coded and entered into Statistical Package for Social Sciences (SPSS) version 21. The description of variables was divided into two, using mean and standard deviation for continuous variables and frequency distributions for categorical variables. Participants who scored more than the mean scores for knowledge, attitude and practice part were classified as having good knowledge, good attitude and good practice. Correlation tests were done to see the association between knowledge and attitude, knowledge and practice, attitude and practice and also the 
correlation of age with knowledge, attitude and practice score among the participants.

\section{RESULTS}

\section{Univariate Analysis}

The total number of participants involved in this study was 121 healthcare workers from Hospital Langkawi, Kedah Darul Aman, Malaysia. The majority of the participants $108(89.3 \%)$ were female. The mean age for the participants was 32.4 (SD: 9.42) years ranging from 22 to 58 years old. More than half of the participants $74(61.2 \%)$ were nurses. The others, 18 (14.9\%), hospital attendant $13(10.7 \%)$ and community nurse nine (7.4\%). There were only three $(2.5 \%)$ medical officers and two (1.7\%) each, of radiographers and assistant medical officers who participated.

The mean score for the knowledge part was 20.9 (SD: 1.88). There were $73(60.3 \%)$ participants who had good knowledge. The minimum score recorded was 16 while the maximum score was 24 . A total of six $(5.0 \%)$ participants managed to get a maximum score of 24 for the part on knowledge. The majority of them $24(19.8 \%)$ achieved a score of 21 . About $118(97.5 \%)$ disagreed that prayers were not obligatory for sick people. All the participants 121 $(100 \%)$ agreed that prayers can be performed while sitting, $112(92.6 \%)$ agreed that it could be performed while lying down and 119 (98.3\%) agreed that it could be performed using the eye movement as symbolic sign.

For the attitude part, the mean score was 46.5 (SD: 3.24). The score ranged from 40 to 55 . About 62 (51.2\%) participants were classified as having good attitude. Most of the participants $17(14 \%)$ obtained a score of 46 . There were two $(1.7 \%)$ participants who managed to get a maximum score of 55 . The majority of the participants $106(87.6 \%)$ strongly agreed that prayers are still obligatory in whatever condition. About $82(67.8 \%)$ participants strongly disagreed that sick people was not obliged to perform prayers. There were also 55 (45.5\%) participants who strongly agreed that Tayyammum was the best alternative for patient who had difficulty in performing ablution.

The median score for the practice part was 8.0 with inter quartiles range of 1.0. The mean score was 7.4 (SD: 0.92). About $73(60.3 \%)$ of the participants were classified as having good practice. The majority of them 109 (90.1\%) performed their obligatory prayers everyday while only 81 (66.9\%) participants still continued to perform their five times daily prayers while sick.

\section{Bivariate Analysis}

Spearman's test was used to see any correlation between age and knowledge, age and attitude, and age and practice score. However, the results were not significant and no correlation was noted between age and knowledge $r(119)=-0.08, p$-value $=0.37$, age and attitude $r(119)=0.01, p$-value $=0.90$, and age and practice $r(119)=0.03, p$-value $=0.73$. There was also no correlation seen between knowledge and practice $r(119)=-0.04, p$-value $=0.69$ and attitude and practice $r(119)=0.13, \quad p$-value $=0.16$. For knowledge and attitude score, Pearson's correlation test was used. The result was also not significant with $r=0.06, p$ value $=0.49$

\section{DISCUSSION}

In general, from the results shown in Figure 1, 2, and 3 , we can see that prior to the training, more than half of the participants were already have good knowledge $(60.3 \%)$, attitude $(51.2 \%)$ and practice (60.3\%) towards religious obligations and Rukhsah. The source of the knowledge may be varied but no specific information was obtained regarding their religious education background. In Malaysia, Islamic education is included as part of the programme since primary schools. These teaching of Islamic values, principles and laws continue until pupils completed their secondary school at the age of 17 . There are also religious schools that are administered by either state governments, Ministry of Education of Malaysia or individuals that offer in-depth study of Islamic in Malaysia. ${ }^{7}$ These are the likely sources of the formal Islamic teaching received by most of the participants.

In every religion, prayer plays an important role as a connection between the believers and God that created them. It is a symbol of worship towards the Almighty. Many believed that prayers can act as a medium that help people to communicate with the "divine and spiritual entities". ${ }^{8}$ For Muslims, prayers act as a strong foundation towards the practice of Islam. It helps Muslims to become closer to Allah and prevent them from doing sinful things. Allah mentioned in the Quran: "Recite, (O Muhammad), what has been revealed to you of the Book and establish prayer. Indeed, prayer prohibits immorality and wrongdoing, and the remembrance of Allah is greater. And Allah knows that which you do". ${ }^{9}$ In a study done by Bloomer et al. in 2013, Muslim patients who were admitted to intensive care units (ICU) in Australia believed that prayers and recitation of Quran had brought them closer to Allah. ${ }^{10}$ Apart from fulfilling their religious obligation, performance of prayers during illness can also help in improving patient's psychological wellbeing and reduce the occurrence of depression, anxiety and distress among them. ${ }^{10}$

Despite all the exemptions given by Allah, not many Muslims are knowledgeable and aware about it. There were many cases of Muslims who did not perform their religious obligations when they are admitted to the hospital. A survey done in Hospital Sultanah Nur Zahirah, Kuala Terengganu in 2007 found that only $20 \%$ of Muslim patients performed their prayers daily throughout their stay in the hospital. ${ }^{11}$ Therefore, it is very important for the 
healthcare providers who are in close contact with the patients in the hospital, to be alert and to remind them regarding their responsibilities.

It is a challenge to improve the awareness among Muslim patients about the importance and obligation of performing prayers while they are sick. Health care providers such as nurses and doctors should have adequate knowledge and input about Rukhsah before they can provide advice to the patients. They need to be confident and comfortable in teaching the patients on how to perform prayers during illness. They should also prepare and equip themselves with substantial information to be ready to anwering questions about Rukhsah from the patients. This can be achieved trough adequate training, coaching and teaching that should be given to all of the healthcare providers. Although some medical schools in Malaysia such as International Islamic University of Malaysia (IIUM) and Universiti Sains Islam Malaysia (USIM) had integrated Islamic input in their medical curriculum, much still need to be done to really disseminate the knowledge to health care workers in Malaysia. $^{12}$

Since no similar study has been conducted earlier in Malaysia, this study helps to evaluate the level of knowledge, attitude and practice among healthcare workers towards religious obligation and Rukhsah in Malaysia. This information is crucial to improve the understanding about the needs of integrating Islamic values and principles in healthcare services specifically in Malaysia. It can also be a good platform to provide religious needs and care to the patient as what had been practiced in Queensland ${ }^{4}$ and Michigan. ${ }^{13}$ A study done by Hammoud et al. in 2005 among Arab Americans and Arab Muslims also concluded that by having good understanding and knowledge on patient's religious needs, a more holistic care can be provided by the healthcare workers. $^{14}$

\section{CONCLUSION}

In conclusion, this study showed that almost half of the participants among healthcare workers in Hospital Langkawi had a good knowledge, attitude and practice on performing prayers during illness Hopefully, by conducting proper training and coaching, their level of understanding towards Rukhsah can be improved. Although the impact of this training programme is yet to be assesed, we hope that knowlegde on prayers and training of the patients will be carried out succesfully by the healthcare workers that we trained.

\section{ACKNOWLEDGMENT}

The authors would like to thank the Ministry of Education, Malaysia for funding this research through 'Knowledge Transfer Programme Grant Scheme' (USIM/KTP/PSK/31/50214) and Hospital
Langkawi for the cooperation given through out the study period.

\section{REFERENCES}

1. Imam Bukhari, Khan MM. The English Translation of Sahih Al-Bukhari. 2. Madinah Al-Munawwarah: Darussalam; 1994. p. 59.

2. Lawrence $P$, Rozmus C. Culturally sensitive care of the Muslim patient. J Transcult Nurs 2001;12:228-33.

3. Imam Bukhari, Khan MM. The English Translation of Sahih Al-Bukhary. 18. Madinah Al -Munawwarah: Darussalam; 1994. p. 300.

4. Queensland Health. Health Care Providers' Handbook on Muslim Patients [Internet]. 2010. 22 p. Available from: http:// www.health.qld.gov.au/multicultural/ health_workers/hbook-muslim.asp

5. The Holy Quran. Sahih International; p. 5:6. Available from: http://quran.com/5/6

6. Latar belakang Hospital Langkawi [Internet]. Hospital Langkawi. 2013 [cited 2015 Oct 5]. Available from: http://hlangkawi.moh.gov.my/ v4/index.php/main-mengenai-kami/mengenaikami/latar-belakang

7. Farid Mat Zain, Mujani WK, Ibrahim Abu Bakar. The Islamic Education and The ' $\mathrm{j}$-QAF' Program in Malaysia 1. Adv Nat Appl Sci 2012;6:310-5.

8. Rezaei M, Adib-Hajbaghery M, Seyedfatemi N, Hoseini F. Prayer in Iranian cancer patients undergoing chemotherapy. Complement Ther Clin Pract 2008;14:90-7.

9. The Holy Quran. Sahih International; p. 29:45. Available from: http://quran.com/29/45

10. Bloomer MJ, Al-Mutair A. Ensuring cultural sensitivity for Muslim patients in the Australian ICU: Considerations for care. Aust Crit Care 2013;26:193-6.

11. Basri I, Burhanuddin A. Sikap Pesakit Terhadap Solat: Kajian di Hospital Kuala Terengganu. Peningkatan Kualiti Dalam Pengajian Islam. Fakulti Pengajian Islam, Universiti Kebangsaan Malaysia; 2007. p. 67-77.

12. Jamilah J, Ahmad Najib A, Dzulkhairi M, Ariff $\mathrm{H}$, Ismail NN. Integration of Islamic Input in Medical Curriculum - Universiti Sains Islam Malaysia (USIM) Experience. Int Med J Malaysia 2014;13:73-7.

13. Padela A, Katie G, and Amal K. Meeting the healthcare needs of American Muslims: challenges and strategies for healthcare settings. Institute for Social Policy and Understanding. June (2011).

14. Hammoud MM, White CB, Fetters MD. Opening cultural doors: Providing culturally sensitive healthcare to Arab American and American Muslim patients. Am J Obstet Gynecol 2005;193:1307-11. 